\title{
O Operar de um Coletivo na WEB ${ }^{1}$
}

\author{
The Operation of a Collective in the WEB
}

Resumo: Analisamos o operar de um grupo de discussão na WEB buscando identificar seu agenciamento enquanto coletivo autoprodutivo. Estabelecemos sete indicadores de operação e cinco categorias temáticas. A visualização de cada um dos indicadores de operação em cada uma das categorias temáticas possibilitou compreender o operar do grupo como decorrente das próprias relações que foram sendo estabelecidas, em um processo autoprodutivo, de causalidade recursiva. Foi possível argumentar que o grupo apresentou indícios de um modo de instituir-se capaz de apontar para outras formas de relação em torno da construção de objetos coletivos teóricos voltados para a ação fora do espaço digital.

Palavras-Chave: WEB, Psicologia Social, grupo.

\section{Karen Eidelwein}

Mestre em Psicologia Social e Institucional/ UFRGS. Docente do Curso de Psicologia da UNIFRA/Santa Maria-RS.

\section{Cleci Maraschin}

Doutora em Educação/ UFRGS. Docente do Instituto de Psicologia, do Programa de PósGraduação em

Psicologia Social e Institucional e do

Programa de Pós-

Graduação em Informática Educativa/ UFRGS.

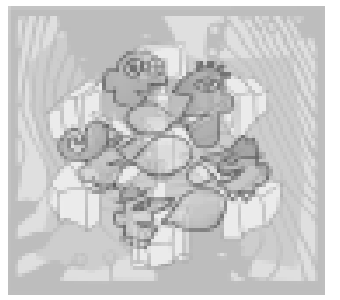

Abstract:We analysed the operation of a discussion group in the WEB trying to identify their management as a self-productive collective. We set up seven operation indicators and five thematic categories. The visibility of each of the indicators in each of the thematic categories made it possible to understand the operation of the group as originated of its own relationships, that were established in a self-productive process of recoursive causality. It was possible to affirm that the analysed group showed traces of a way of constitution able to indicate other ways of relationship related to the construction of theoretical collective objects that aimed an action out of the digital space.

Key-words: WEB, social Psychology, group.

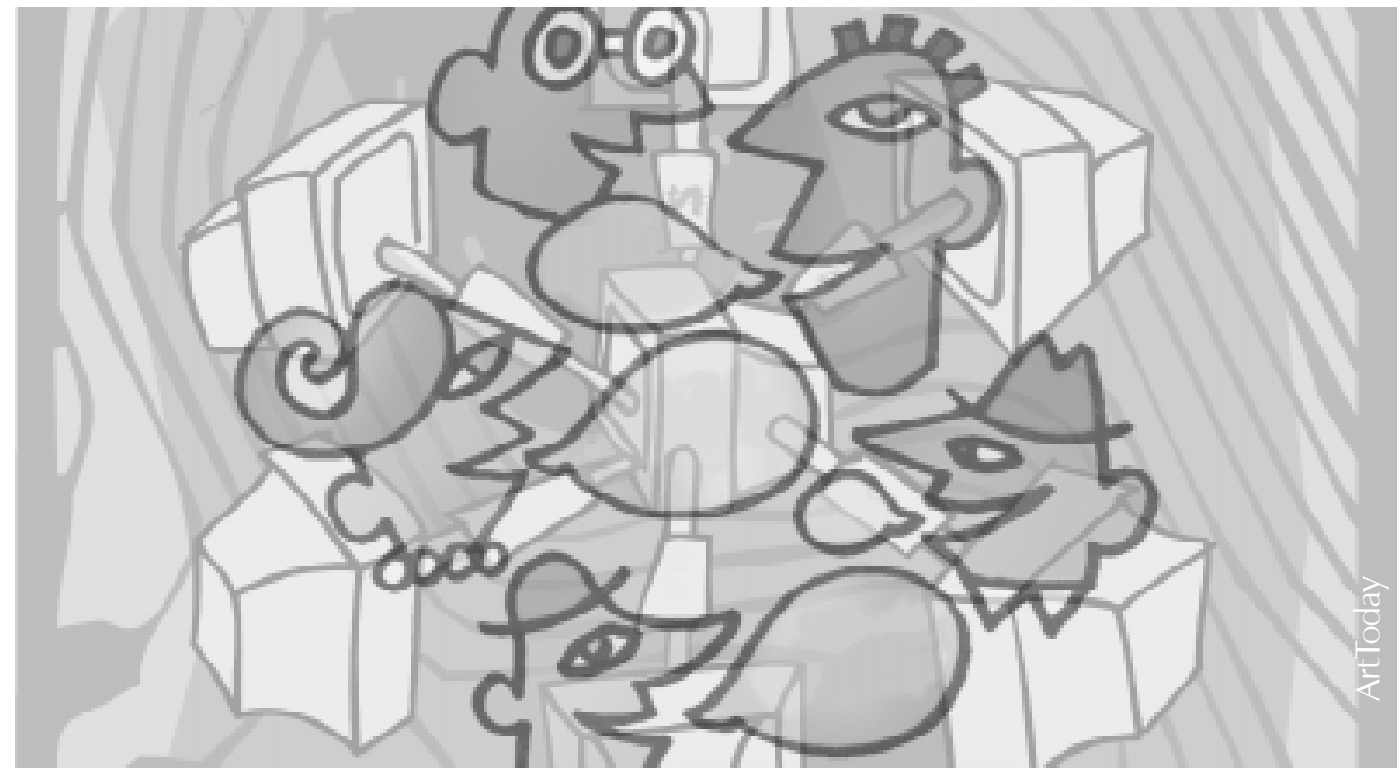

O presente artigo é um desdobramento da pesquisa de mestrado, atualizada na dissertação "CIBERIDÉIAS - construindo modos de conhecer-trabalhar" (Eidelwein, 2001), e visa a apresentar o operar de um grupo de discussão à distância, via e-mail, como um coletivo autoprodutivo.

Para Lévy (1998), os recursos tecnológicos poderiam dar condições para a constituição de uma grupalidade autoprodutiva organizada em torno de propósitos construídos a partir de relações baseadas em uma demodinâmica, ou seja, uma democracia participativa, em tempo real, onde os sujeitos se engajam diretamente nas discussões e decisões, sem transferir a outrem (um representante) seu poder de decisão e escolha sobre os assuntos de interesse desse mesmo coletivo.

A crescente presença de interações mediadas pelo computador, em vários domínios de existência, faz com que sejam objeto de estudos recentes. Busca-se mapear as produções subjetivas (Turkle, 1997), as modalidades interativas (Axt; Maraschin, 1999, Eidelwein, Maraschin, 2000) e as produções cognitivas (MARASCHIN, 1993, MAZZOCHI, 2001). Como sustentar ou criticar os propalados agenciamentos de tal acoplamento grupal? É dentro dessa perspectiva que se inscreve o presente trabalho. 
Buscou-se acompanhar a interação escrita de um grupo de discussão virtual para inferir se poderíamos tomá-lo como um coletivo autoprodutivo.

A idéia de um operar coletivo adjetivado como autoprodutivo (ou inteligente) ${ }^{2}$ é proposta por Lévy (1998) quando o autor apresenta a dinâmica política de uma cidade inteligente (demodinâmica) que deveria ou poderia se basear em sete grandes fases: ESCUTA, EXPRESSÃO, DECISÃO, AVALIAÇÃO, ORGANIZAÇÃO, CONEXÃO e VISÃO.

Embora tais fases se refiram à dinâmica política de uma inteligência coletiva macrossocial - uma cidade inteligente - no presente estudo elas serviram de base para a análise da dinâmica política de um coletivo microssocial - um grupo de discussão na WEB. Tal apropriação decorre do entendimento de que um coletivo macrossocial é constituído, ao mesmo tempo que constitui, por uma série de pequenos coletivos inteligentes e que as relações macrossociais se reproduzem em espaços microssociais. Diante disso, a caracterização de cada uma das fases acima mencionadas adquire novos significados quando referida a um contexto microssocial. Dessa forma, passam a ser denominadas indicadores de operação do coletivo, pois será a visualização de cada uma, a partir das mensagens eletrônicas enviadas ao grupo, que possibilitará argumentar sobre o operar desse enquanto coletivo autoprodutivo.

A análise do movimento do grupo, considerando-se as relações entre os indicadores de operação e as categorias temáticas construídas a partir dos conteúdos das mensagens eletrônicas trocadas entre seus participantes, possibilitou identificar um processo autoprodutivo. O modo de funcionamento do grupo de discussão em questão permitiu observar dois movimentos concomitantes. Um, voltado para seu funcionamento interno, autoprodutivo no estabelecimento e manutenção de uma rede de relações que caracterizam o grupo - seu fechamento enquanto sistema - ; outro, relacionado à dinâmica de interação na própria WEB (abertura), decorrente da política de funcionamento do grupo estabelecida no momento de sua criação junto ao site hospedeiro, determinando seu funcionamento em termos de assinatura, moderação, envio e recebimento de mensagens, ou seja, seu movimento de abertura ao espaço virtual, o ingresso e a permanência dos interlocutores sustentados apenas na própria interação. Tais movimentos encontram-se interrelacionados, afetando-se mutuamente. O movimento de abertura afeta o grupo, na medida que cada integrante pode se conectar ou se desconectar sem aviso prévio nem convite ou que mensagens enviadas por remetentes estranhos ao grupo adentrem as caixas postais virtuais de seus integrantes. O grupo, a partir dessa organização, pode operar em várias direções e de várias formas diante do ingresso de um novo integrante ou do recebimento de uma mensagem desconhecida, podendo, inclusive, propor alterações nas configurações de abertura do coletivo ao ciberespaço.

\section{O Grupo Visível na Rede}

O grupo de discussão Ciberidéias ${ }^{3}$ foi constituído através de um processo de divulgação/convite, via rede telemática, que consistiu no envio de uma série de mensagens para instituições representativas de vários setores de trabalhadores, assim como para particulares, que pudessem contribuir para divulgar a idéia do grupo a pessoas interessadas em participar. O Ciberidéias propunha-se a servir de um espaço digital de discussão em torno de questões tais como: mudanças atuais no campo do trabalho/emprego, novas tecnologias de informação e comunicação (NTIC) e a relação entre educação e trabalho, dentre outros temas de interesse do próprio grupo. Cabe destacar que o ingresso no grupo já significava estar a pessoa de acordo com o fato de que as informações trocadas no mesmo poderiam vir a contribuir para a elaboração da pesquisa, conforme exposto na mensagem de boas-vindas recebida pelos sujeitos que ingressavam no grupo.

Após o processo de divulgação/convite do e para o grupo de discussão, verificou-se que as pessoas que se conectaram, em número de vinte na época da pesquisa, possuíam, em grande maioria, grau de escolaridade superior completo. Dessas vinte pessoas, dez responderam a um questionário enviado ao grupo com o objetivo de conhecer alguns indicadores sociais dos participantes: apenas duas possuíam emprego formal, três eram estudantes (duas com bolsa de estudo), quatro eram autônomos (uma pessoa ressaltou a condição de autônomo desocupado e outra de autônomo sem direito de espécie alguma) e uma pessoa declarou-se sem emprego. Em relação ao acesso ao ciberespaço: oito pessoas conectavamse da própria residência (três também do local de trabalho) e apenas duas do local de trabalho.

Embora o interesse da constituição do grupo fosse contar com pessoas desempregadas ou na iminência da perda do emprego, o grupo configurado era diferente. A ausência dos sujeitos inicialmente imaginados pode servir como um elemento reforçador da realidade de que tais sujeitos ainda se encontram submetidos a um estado de manuntenção da ignorância que lhes nega a oportunidade de acesso e a apropriação de um outro meio de informação, que constitui, ao mesmo tempo, outra possibilidade de inserção social, assim como vêm sendo alijados de outras tantas redes de relações sociais, seja a educação, seja o trabalho.

A presença de sujeitos com nível elevado de escolaridade, algum poder aquisitivo, uma vez que muitos acessavam a Internet da própria casa, e relações
1 Entenda-se WEB como sinônimo de Ciberespaço.

2 Neste trabalho, a expressão coletivo autoprodutivo é utilizada como sinônimo de coletivo inteligente.

3 http://www.grupos.com.br/ grupos/ciberideias. 
de trabalho diversificadas, onde apenas duas pessoas possuíam relações de trabalho/emprego dentro de uma "cultura da estabilidade", enquanto os demais, estudantes, autônomos e sem emprego, encontramse em relações baseadas na instabilidade, na incerteza, muitas vezes na precariedade, remete-nos à idéia de que o desemprego vem atingindo trabalhadores não só de baixa escolaridade. Apesar da instabilidade vivida nas relações de trabalho, talvez se possa dizer que, em função do maior nível de escolarização e, em decorrência dele, dos meios nos quais tais sujeitos circulam e interagem, esse é o público que mais facilmente tem acesso à Rede e interesse em navegar. As informações fornecidas, considerando que somente a metade dos integrantes do grupo respondeu às questões do questionário, vêm ao encontro, pelo menos em parte, do perfil das pessoas com acesso à Rede.

Os usuários do ciberespaço são em sua maioria pessoas jovens, com diploma universitário, vivendo em cidades, estudantes, professores, pesquisadores, trabalhando geralmente em áreas científicas, de alta tecnologia, negócios ou arte contemporânea (Lévy, 1999, p. 213).

\section{Os Indicadores de Operação}

"Os usuários do ciberespaço são em sua maioria pessoas jovens, com diploma universitário, vivendo em cidades, estudantes, professores,

pesquisadores,

trabalhando

geralmente em

áreas científicas, de alta tecnologia, negócios ou arte contemporânea"

4 Entenda-se por modos de conhecer-trabalhar as operações fisico-mentais, ou seja, as relações entre as ações do corpo físico $e$ as capacidades cognitivas dos sujeitos, que são acionadas-ativadas durante os processos de trabalho/emprego, conforme Eidelwein (2001).
Na busca por compreender as relações que foram se estabelecendo entre os participantes do Ciberidéias, com o objetivo de poder identificar até que ponto o grupo conseguiu operar enquanto coletivo autoprodutivo, foi necessário caracterizar os indicadores de operação de um coletivo inteligente a partir de cada uma das sete fases descritas por Lévy (1998), considerando suas diferenças de amplitude, uma vez que se busca visualizá-los como indicadores de operação de um micro coletivo:

A escuta, atitude pela qual cada membro do grupo busca conhecer os demais participantes, apreendendo a própria inserção como produção de efeitos na constituição do Ciberidéias, dá voz e nitidez à variedade interna, às diferenças que compõem o próprio coletivo. Configura-se como possibilitadora, espaço/tempo de sustentação que dá visibilidade ao pronunciamento e à exposição de idéias, projetos, argumentos, pensamentos, saberes, relações etc. através de mensagens escritas, imagens e/ou sons. Caracteriza-se como processo constitutivo do coletivo, estabelecendo uma circularidade criadora aberta. A possibilidade de ser ouvido pelas singularidades que compõem o grupo fornece ao coletivo meios de compreender-se como tal, uma escuta molecular de cada um dos sujeitos possibilitadora de um processo de emergência do agenciar diversos modos de conhecer-trabalhar ${ }^{4}$ em função da diversidade que o constitui. grupo enquanto coletivo autoprodutivo capaz de
O processo de escuta contínua, embora não seja uma condição suficiente, favorece e promove a expressão das idéias, questionamentos, opiniões, informações, experiências, saberes, comentários etc. que parecem aos sujeitos mais pertinentes de serem compartilhados com o grupo através das mensagens enviadas. A escuta de cada uma das mensagens possibilita a interconexão de idéias, experiências e sentimentos singulares e coletivos que se atualizam na forma de novas mensagens, criando uma rede que se (re)alimenta a cada nova expressão dos argumentos e das posições reveladoras das idéias de cada um. Ao serem compartilhados no e com o grupo, tais argumentos e posições diluem-se, passando a fazer parte do mesmo como uma totalidade, um pequeno coletivo.

Os processos de expressão e escuta abrem espaço para a conexão, isto é, para a manifestação de elementos problematizadores, desorganizadores e desestabilizadores do movimento do grupo e das idéias dos sujeitos, possibilitando outros caminhos até então impensados, tais como: (re)agrupamentos imprevistos, desejos de trocas e colaboração, ampliação e aprofundamento das discussões ou até mesmo a desintegração do grupo, considerando o princípio dialógico apresentado por Morin (1991), caso aquele não consiga manter sua organização diante de uma perturbação. A conexão é o indicador que dá movimento ao grupo, possibilita a expressão da criatividade e abre espaços para o imprevisível, exigindo constantes adaptações do coletivo diante de novas situações. Exprime-se através das idéias dos sujeitos que buscam problematizar, questionar e ampliar as discussões, ou mesmo propor um novo ponto de abertura cujos efeitos são desconhecidos pelo próprio grupo. Além disso, a entrada de um novo componente também é considerada um movimento de conexão, uma vez que modifica a estrutura do coletivo. Junto ao movimento de conexão, os processos de escuta e expressão abrem caminho para a avaliação e a visão.

A avaliação refere-se aos movimentos de expressão de idéias e sentimentos em relação ao próprio grupo. Apresenta-se como a possibilidade de os sujeitos compartilharem com os demais os significados que vêm atribuindo ao grupo e a importância que este vem adquirindo em suas vidas. Possibilita pensar sobre os objetivos do coletivo, sobre o seu próprio papel enquanto ator no processo de participação e construção do grupo. O processo de avaliação pode ser compreendido como uma nova conexão no grupo com potencial de abrir caminhos antes impensados como, por exemplo, a construção de ações coletivas que extrapolem a realidade on-line, favorecendo, para isso, a emergência da visão, um processo que surge "das interações e dos contatos, forja-se nos projetos comuns, nas circulações e encontros" (Lévy, 1998, p. 73). Permite visualizar a 
inscrição dos processos moleculares (singulares) no coletivo ao mesmo tempo que possibilita a integração do coletivo à sua experiência. Reflete-se e fragmentase nos projetos e estratégias individuais, orienta ou polariza os processos moleculares. Os sujeitos, a partir da avaliação das potencialidades, interesses, experiências e recursos que constituem o coletivo, passam a compartilhar suas idéias, ideais e sonhos de criar outros caminhos para o grupo, apresentando propostas e sugestões que servem como novas conexões para a abertura de espaços de decisão e organização. A decisão, compartilhada e descentralizada em relação ao que será operacionalizado pelo coletivo quanto às ações a serem colocadas em prática, abre espaço para a organização do coletivo em torno daquilo que pretende realizar. Papéis são distribuídos, funções são repartidas, forças, saberes e habilidades são reunidas, em um processo de participação aberto e em tempo real.

Todos esses indicadores de operação podem acontecer de forma simultânea no operar do grupo, ao qual se encontram interligados em um processo de cooperação, entendido aqui como "... operar em comum, isto é, ajustar por meio de novas operações [...] de correspondência, reciprocidade ou complementaridade, as operações executadas por cada um dos parceiros" (PIAGET, 1973, p. 105).

\section{Análise das Mensagens}

Considerando o grupo constituído e buscando visualizar os indicadores de operação através das mensagens trocadas entre os participantes, foram construídas cinco categorias temáticas a partir do levantamento dos conteúdos de noventa e uma mensagens, selecionadas dentro de um universo de duzentos e oitenta, enviadas de junho a outubro de 2000 para o Ciberidéias. O critério de seleção foi a relação entre o conteúdo das mensagens e os objetivos iniciais do grupo. Foram constituídas as seguintes categorias:

Modos ou formas de inserção no grupo - referemse às mensagens de ingresso dos sujeitos no Ciberidéias. As pessoas, ao se conectarem ao grupo, apresentavam-se de maneiras diferentes.

Idéias em discussão - dizem respeito às mensagens que abordaram assuntos diretamente vinculados aos objetivos do grupo e foram trazidas para a discussão: a relação entre trabalho e emprego, entre tecnologia informática e desemprego, entre inclusão x exclusão, dentre outras questões.

Referência e/ou reflexões sobre o próprio grupo categoria temática construída a partir das mensagens nas quais os sujeitos faziam algum tipo de comentário sobre o funcionamento do próprio grupo.
Interconexão com experiências off-line - categoria construída a partir de mensagens nas quais foram compartilhadas experiências de trabalho, de estudo e de vida na realidade off-line.

Articulação para a realização de ações na realidade off-line - categoria construída a partir de mensagens que propunham a organização do grupo em torno de ações a serem concretizadas na realidade off-line.

\section{O Operar do Ciberidéias}

Buscou-se identificar em cada uma das referidas categorias os indicadores de operação de um coletivo autoprodutivo. Para tanto, o universo das noventa e uma mensagens eletrônicas selecionadas foi distribuído para as cinco categorias, conforme o conteúdo que abordavam. Em cada uma das mensagens, efetuou-se o levantamento dos indicadores presentes conforme a caracterização de cada um.

Na categoria modos ou formas de inserção no grupo, encontramos a expressão (53\%) e escuta (19\%) com maior incidência, seguidos pela conexão e avaliação, ambos com $14 \%$. Talvez se possa dizer que o movimento de ingresso no grupo implica muito mais a necessidade de algum tipo de apresentação pessoal, buscando fazer-se notar, marcar a presença no coletivo, do que explicitar ou mesmo exercer um movimento de escuta. Nas mensagens em que a escuta foi explicitada, geralmente foi acompanhada de movimentos em que os sujeitos fizeram alguma referência ao grupo, trazendo elementos, mesmo que incipientes, na forma de questionamentos que abriram espaço para outras questões e discussões, originando novas mensagens.

A categoria idéias em discussão mobilizou a expressão e a escuta, ambos com $40 \%$, a conexão $(17 \%)$, a avaliação (4\%) e a visão (1\%). Pode-se dizer que o movimento de discussão de idéias altera consideravelmente a relação entre os indicadores expressão e escuta quando comparada à categoria temática anterior. Tal situação talvez seja decorrente da necessidade, em um processo de discussão, do exercício da capacidade de as pessoas escutarem-se umas às outras, assim como ao próprio coletivo, favorecendo, dessa forma, a expressão de outras tantas idéias. Pode-se pensar que a tematização (refletir sobre determinada idéia ou assunto) produz a construção de um objeto coletivo de pensamento, objeto esse que permite diferentes posições não necessariamente consensuais.

Nessa categoria temática, a expressão e a escuta tornam-se fundamentais para que os sujeitos possam participar das discussões. Cada mensagem enviada pode ser compreendida como uma expressão 
decorrente de uma escuta que, mesmo não sendo explicitada, pode ser reconhecida através do tema ou assunto expresso em uma mensagem subseqüente que dá continuidade à discussão. $\bigcirc$ operar desses indicadores vai abrindo espaço para a conexão. $\mathrm{O}$ indicador possibilita ao grupo dinamizar, problematizar e aprofundar as discussões, cuja valorização passa a ser expressa pelo coletivo através dos indicadores de avaliação e visão. A importância da construção coletiva de objetos de pensamento abre espaço para que os sujeitos passem a fazer referências ao grupo, tanto no sentido de mencionar seus objetivos, a percepção que possuem do mesmo e a importância que vem adquirindo para cada um como na direção de imaginar novos sentidos e significados para o coletivo.

\section{A intensidade e freqüência que os pacientes, em especial as crianças, depositam seus conteúdos inconscientes no terapeuta, sugerem o quanto o preparo técnico e pessoal pode favorecer o manejo da contratransferência.}



Na categoria referência e/ou reflexões sobre o próprio grupo, foi possível identificar a avaliação $(24 \%)$, seguida pela expressão e escuta, ambas com $23 \%$, a conexão (15\%), a visão (12\%) e a organização (3\%). Talvez se possa dizer que, dentro do movimento de referir-se ao próprio coletivo, a expressão e a escuta permanecem sendo importantes indicadores de operação, permitindo aos sujeitos expressar o que pensam a respeito do grupo, qual compreensão vêm estabelecendo sobre ele, como se sentem ao participar das discussões etc., abrindo espaço para a construção de uma avaliação coletiva do próprio grupo. São manifestações singulares que, ao serem compartilhadas com os demais integrantes, se diluem, adquirindo novas conformações que podem contribuir para ampliar a visão do próprio coletivo em relação a suas possibilidades de ação, promovendo iniciativas de organização.

Cabe destacar que o movimento de auto-referência de um grupo de discussão à distância ocorre com freqüência. De acordo com Axt e Maraschin (1999), talvez o movimento do grupo de auto-referir-se possa ser pensado como de caráter autopoiético, uma vez que o pensar e o dizer do grupo sobre si;
... opera como um possibilitador de retroalimentação, favorecendo voltar sobre o percorrido e, no movimento de repetição, inovar o caminho fazendoo diferente, pois, se há repetição do movimento, não se pode dizer o mesmo com referência ao caminho, o trajeto percorrido é irreversível, pois irreversível é o tempo e o contexto - e se o caminho é, de algum modo, diferente, é essa diferença que acaba por abrir novas possibilidades (Axt; Maraschin, ibidem, p. 40).

Na categoria interconexão com experiências off-line, visualizamos os seguintes indicadores de operação: expressão (46\%), escuta (38\%), conexão $(8 \%)$, avaliação e organização, ambos com $4 \%$. Nessa categoria temática, a expressão e a escuta das experiências singulares, atravessadas por alguns questionamentos e problematizações, promovem o aparecimento de referências ao grupo e de propostas de organização, à medida que as pessoas vão conhecendo-se mais, através de seus trabalhos, e passam a compartilhar de forma mais efetiva objetivos e interesses em comum. Mais uma vez, a escuta e a expressão apresentam-se como indicadores de operação importantes no reconhecimento e valorização das experiências singulares e significativas de trabalho, estudo, pesquisa, dentre outras, compartilhadas pelos sujeitos, pois potencializam a manifestação de interesses em realizar ações que conectem as diferentes habilidades, conhecimentos e saberes de cada um.

Finalmente, na categoria articulação para a realização de ações na realidade off-line, encontramos: expressão (27\%), escuta (26\%), organização $(20 \%)$, visão (9\%), conexão e avaliação, ambos com 7\%, e decisão (4\%). O processo de articulação para a realização de ações na realidade off-line implica que os sujeitos expressem suas propostas, as quais necessitam ser escutadas, problematizadas e questionadas por conexões que promovam a avaliação e a visão do grupo, que contribuirão para a decisão e organização em torno das idéias e/ou projetos que o coletivo busca operacionalizar. Esse fato permite supor que, quando os sujeitos estabelecem entre si a perspectiva de um projeto comum, resultante da vontade de entendimento e cooperação, se esteja diante de um coletivo que opera com todos os indicadores distinguidos.

Até aqui foi possível observar o agenciamento dos indicadores de operação de um coletivo inteligente em cada uma das categorias temáticas construídas. Porém, uma vez que tais categorias se encontram relacionadas, operando de forma simultânea no grupo através das várias mensagens que podem ser inseridas em mais de uma delas, foi construída a fig. 1, que possibilita a visão geral de cada um dos indicadores, considerando todas as categorias referidas. 


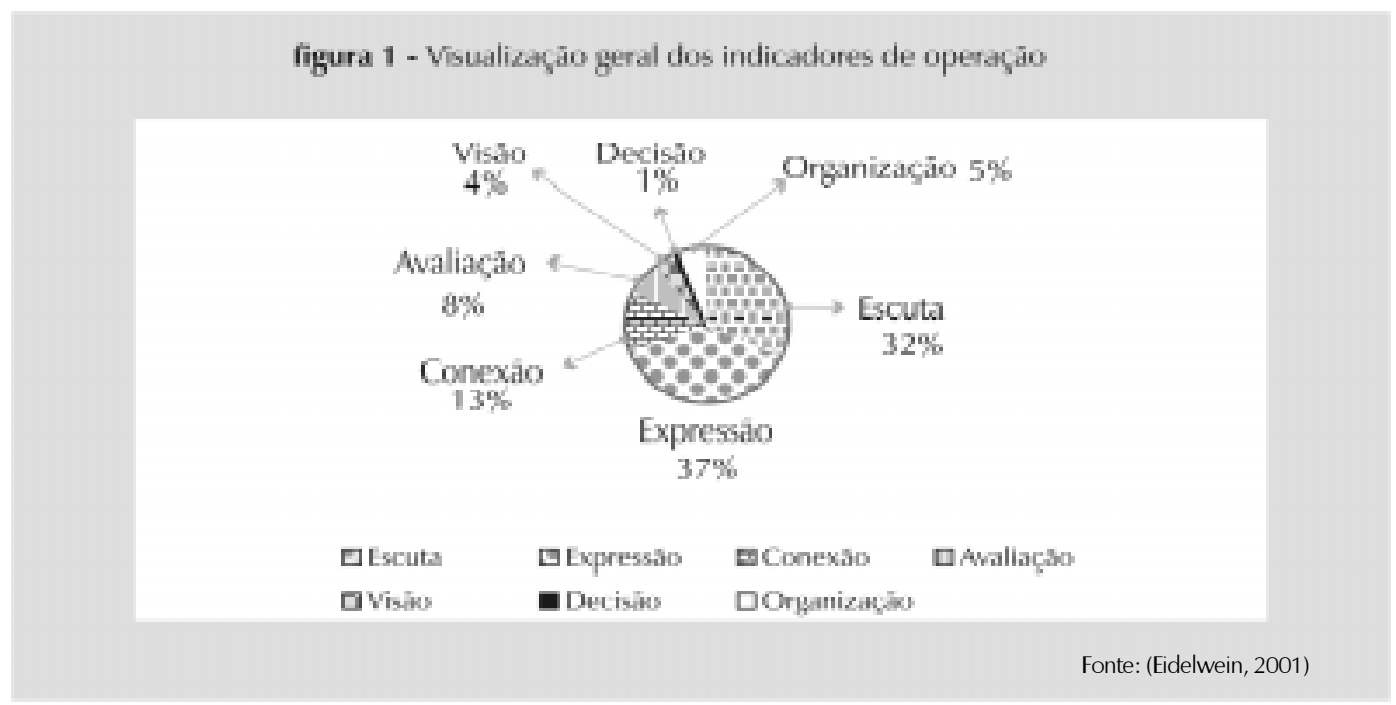

A partir dos dados da fig. 1, os indicadores de operação predominantes no movimento do grupo foram a expressão e a escuta, seguidos pela conexão, avaliação, organização, visão e decisão. Diante disso, pode-se dizer que a expressão e a escuta foram os indicadores fundamentais para a constituição do Ciberidéias como grupo de discussão autoprodutivo à distância, que não se limitou à troca de informações. As discussões em torno de vários assuntos, que podem ser entendidas como um processo de construção de objetos de pensamento, foram tornando-se complexas à medida que novos elementos eram trazidos, problematizados e questionados. A presença de experiências off-line remetidas ao grupo enriqueceu as possibilidades de expressão e conexão no e com o mundo on-line. $\mathrm{O}$ movimento de retorno recorrente entre as mensagens contribuiu para que o grupo pudesse retomar sua história e com isso rever, questionar e problematizar posicionamentos e argumentos em direção a um processo cada vez mais articulado, complexo e acolhedor das multiplicidades conectadas.

\section{A Possibilidade de um Operar Autoprodutivo}

As mensagens enviadas ao grupo, que possibilitaram a construção das categorias temáticas, podem ser compreendidas tanto como efeitos do agenciamento dos indicadores de operação desse coletivo quanto meios para esse agenciamento. Essas mensagens geram o grupo que, por sua vez, gera outras tantas mensagens em um processo autoprodutivo.

A análise dos dados obtidos através das mensagens enviadas ao grupo de discussão ajuda a pensar e explicitar o mecanismo através do qual supomos que o Ciberidéias possa ser considerado um coletivo autoprodutivo: um mecanismo que surge como efeito do próprio operar do coletivo, ao mesmo tempo em que é estrutura desse operar. O grupo, enquanto unidade composta, apresentou uma estrutura, constituída pelos integrantes que dele participaram e pelas relações entre eles, e uma organização, que surgiu como subproduto das relações entre os integrantes do coletivo, conferindo-Ihe sua identidade. Dessa forma, as relações entre os integrantes do Ciberidéias, estabelecidas através do envio de mensagens eletrônicas, podem ser consideradas produtoras do próprio coletivo que, por sua vez, ao manter sua organização (identidade) enquanto tal possibilitou a produção das relações que o mantiveram. Trata-se de uma explicação causal em forma de anel. "Uma causalidade recursiva, onde [...] os efeitos e os produtos são necessários no processo que os gera. O produto é produtor daquilo que [o] produz" (Morin, 1991, p. 105). Dentro desse processo, os indicadores de operação definidos - escuta, expressão, conexão, avaliação, visão, decisão e organização - ativaramse reciprocamente, criando um processo de automanutenção ou autoprodução do próprio coletivo através de um movimento recursivo, e não meramente repetitivo, entre as mensagens enviadas ao grupo.

Há uma recursão sempre que um observador pode afirmar que uma operação é realizada sobre a conseqüência de sua aplicação prévia. Há uma repetição sempre que um observador pode afirmar que uma dada operação é realizada de novo, independentemente das conseqüências de sua realização prévia. Então, o que faz com que a ocorrência recorrente de uma dada operação seja uma recursão ou uma repetição é o tipo de associação que ela mantém com algum outro processo (Maturana et. al., 1997, p. 217). 
Foi possível observar um intenso movimento recursivo cooperativo em torno da construção de objetos de pensamento (idéias, teorias, conceitos), que se ampliou na direção do desejo coletivo de articulação para operacionalização de ações na realidade offline (quem sabe a realização de algum projeto social em conjunto). Talvez se possa dizer que tenha sido implantado um movimento criativo e de abertura para possibilidades decorrentes das relações estabelecidas entre os integrantes do grupo, a partir de operações de correspondência, reciprocidade ou complementaridade, evidenciadas através dos indicadores de operação visualizados. Partindo do estabelecimento de algumas regras, as mais flexíveis e disponíveis no momento de criação do grupo junto ao site hospedeiro, possibilitando a participação de quem se interessasse, sem controle das mensagens recebidas e sem hierarquia entre os participantes, pode-se dizer que a dinâmica das relações estabelecidas entre os integrantes do grupo foi determinante para seu crescimento como coletivo autoprodutivo emergente. inteligente traball

tanto quanto possive suas velocidades de aprendizado, aumenta suas capacidades de reorganização, reduz seus prazos de

inovação, multiplica seu potencial inventivo.

[...] Mas ele só atingirá essa velocidade

cognitiva mobilizando - e portanto respeitando - as subjetividades autônomas que o compõem, em vez de alinhá-las em um tempo exterior. O tempo real da inteligência coletiva só pode ser uma emergência; ele

sincroniza intensidades

de pensamento, de aprendizado e de vida"
Os modos ou formas como cada sujeito ia aderindo ao grupo, a qualquer tempo, além de implicar a capacidade de escuta por parte daqueles que a ele já pertenciam, significou a possibilidade de expressão e conexão em um novo espaço a ser explorado pela própria abertura que tal inserção promovia. A expressão de idéias, sentimentos, posicionamentos e informações, organizadas de forma singular pelos sujeitos que enviavam a mensagem, também aparecia como nova conexão no e do grupo, uma vez que possuía a potencialidade de desviar, agregar, entortar, abrir um outro caminho para as discussóes que já vinham se processando. A interconexão com experiências off-line e a articulação para a realização de ações na realidade off-line podem ser compreendidas como fruto do processo de escuta, expressão e conexão, ao mesmo tempo que, à medida que eram compartilhadas com e construídas pelo coletivo, realimentavam os referidos processos, permitindo a visualização de outros indicadores de operação, tais como a organização e a decisão. Todo esse movimento foi atravessado por tímidas referências e/ou reflexões sobre o próprio grupo, explicitando os indicadores de avaliação e visão. Embora todos os indicadores de operação tenham sido visualizados ao longo do movimento do grupo, o fato de o acontecimento da expressão, escuta e conexão terem sido os mais freqüentes em relação à avaliação, organização, visão e decisão, talvez possa ser compreendido quando se pensa nas temporalidades de constituição e de ação de um coletivo, apresentadas por Lévy (1998). Para esse autor, a temporalidade de constituição

... é forçosamente "lenta", e não pode se manifestar de imediato, em segundos. Se pressionada, ela se esquiva, justamente porque é autônoma. Sem dúvida lançará mão do tempo real das técnicas moleculares e das redes digitais, mas para melhor acompanhar um ritmo interior, subjetivo, secreto, plural e complicado, que não pode ser medido nem pelo relógio nem pelo calendário (Lévy, ibidem, pp. 74-75).

Já quanto à temporalidade de ação, o referido autor afirma que

... o coletivo inteligente é efetivamente mais 'rápido' que os grupos humanos orgânicos ou molares. [...] A técnica, a linguagem, o pensamento em geral são aceleradores. É por isso que o coletivo inteligente trabalha tanto quanto possível suas velocidades de aprendizado, aumenta suas capacidades de reorganização, reduz seus prazos de inovação, multiplica seu potencial inventivo. [...] Mas ele só atingirá essa velocidade cognitiva mobilizando - e portanto respeitando - as subjetividades autônomas que o compóem, em vez de alinhá-las em um tempo exterior. O tempo real da inteligência coletiva só pode ser uma emergência; ele sincroniza intensidades de pensamento, de aprendizado e de vida (Lévy, ibidem, p. 75).

Talvez o Ciberidéias, por ser um coletivo autoprodutivo, permaneça sempre em construção e por isso a expressão, a escuta e a conexão apareçam entre os indicadores de operação mais exercitados. Entretanto, o desejo coletivo de operacionalizar algo na realidade off-line pode ser compreendido como manifestação da temporalidade de ação do grupo. Considerando que o tempo ou os tempos do coletivo se interconectam, implicando o fato de cada ação ser compreendida como uma possibilidade de reconstituição do próprio coletivo, o Ciberidéias apresenta a potencialidade de operar em forma de coletivo autoprodutivo passível de se atualizar em outros domínios de ação. Observou-se a busca em realizar ações que contemplem os objetivos e interesses de seus integrantes para além da realidade on-line, considerando a visão crítica que possuem da realidade social na qual se encontram inseridos.

Nessa direção, e lançando o olhar sobre o Ciberidéias no sentido de grupo que busca concretizar ações sobre a realidade off-line, pode-se compreendê-lo como meio potencializador e visualizador de outros modos de conhecer-trabalhar. A possibilidade de cada um de seus membros compartilhar seus conhecimentos, habilidades e saberes, reconhecendo-se autores desse espaço de construção, buscando identificar as semelhanças e diferenças que os constituem, quais recursos se encontram disponíveis e quais os caminhos a serem percorridos, de forma que todos os interessados participem do processo de construção de uma idéia ou de um projeto desde o seu início, significa uma outra forma de produção de conhecimento e de relação com o trabalho. $O$ sujeito passa a poder dispor de seu tempo, dentro de uma rede solidária, participativa e de cooperação em torno da troca de 
idéias e informações e da construção de ações que podem significar outra lógica de pensamento e ação capaz, quem sabe, de pulverizar a lógica capitalista de viver.

Como bem diz Mance (1999), ao desenvolver a questão das redes de colaboração solidária, a tecnologia informática (digital) não é indispensável para a constituição e operacionalização de tais redes; entretanto, se acoplada a elas, pode facilitar a organização e expansão das mesmas. Ainda considerando as idéias do referido autor sobre o sistema de informação das redes de colaboração solidária, quando diz que "... toda informação deve fluir livremente pela rede ..." (Mance, ibidem, p. 69), entendemos que a comunicação via WEB pode servir como importante recurso tecnológico para produzir outras comunicações e realidades.

Os coletivos autoproduzidos no espaço digital podem construir experiências e modos de ação na dita realidade off-line. Além de ser apenas um novo meio de interação com idéias, imagens e símbolos, sua constituição reticular, a quantidade e a diversidade de informações que interliga em alta velocidade e a possibilidade de as pessoas comunicarem-se em vários espaços virtuais de interação vão contribuindo para modificar as capacidades cognitivas humanas e sociais, essas últimas organizadas pela rede de instituições sociais. Talvez contribua para a compreensão e o entendimento de que o próprio sujeito vive como uma rede, ou seja, que sua subjetividade é potencializada pelas relações que constitui e mantém ao longo de sua existência. A possibilidade de constituição de coletivos autoprodutivos nesse espaço, em torno da operação de objetos coletivos teóricos e/ou voltados para projetos de ação, dinamizados pela comunicação em tempo real e por uma topologia reticular do conhecimento, pode ser pensada como efeito de uma outra inteligência social, baseada na valorização e reconhecimento das potencialidades dos sujeitos singulares (embora sempre múltiplos) assim como dos grupos, promovendo outros espaços para a construção de laços sociais tecidos, quem sabe, por redes de interação mais democráticas e solidárias.

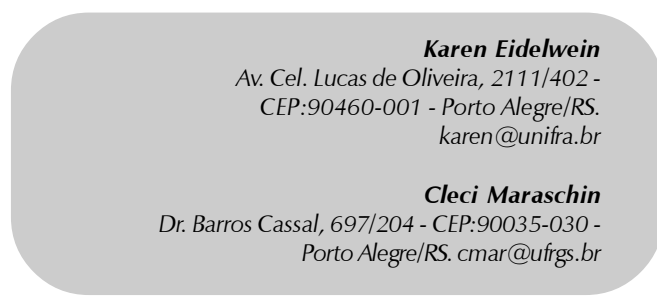

AXT, Margarete, MARASCHIN, Cleci. Narrativas Avaliativas Como Categorias Autopoiéticas do Conhecimento. Revista de Ciências Humanas, Florianópolis, v.1, n.1, 1999, pp. 21-41

EIDELWEIN, Karen, MARASCHIN, Cleci. Encontros Presenciais \& Virtuais: Espaços de Construção de Coletivos Inteligentes. Informática na Educação: Teoria \& Prática. Porto Alegre: Pós-Graduação em Informáticana Educação/ UFRGS, v.3, n.1, 2000, pp. 151-160

EIDEIWEIN, Karen. CIBERIDÉIAS - Construindo Modos de ConhecerTrabalhar. Porto Alegre: UFRGS, 2001. Dissertação de Mestrado, Instituto de Psicologia, Universidade Federal do Rio Grande do Sul, 2001.

LÉVY, Pierre. As Tecnologias da Inteligência, o Futuro do Pensamento na Era da Informática. Rio de Janeiro:Editora 34, 1993.

A Inteligência Coletiva. São Paulo:Loyola, 1998.

Cibercultura. São Paulo/SP:Editora 34, 1999.

MANCE, Euclides A. A Revolução das Redes - a Colaboração Solidária Como uma Altemativa pós-Capitalista à Globalização Mundial. Petrópolis/ Rj:Vozes, 1999.
MARASCHIN, Cleci. Palavras Mágicas. Educação e Realidade, Porto Alegre, v.18, n.1, 1993, pp. 71-80.

O Escreverna Escola: da Alfabetização ao Letramento. Porto Alegre: UFRGS, 1996. Tese de Doutorado em Educação, Faculdade de Educação, Universidade Federal do Rio Grande do Sul, 1996.

MATURANA, Humberto R. et. al. A Ontologia da Realidade. Belo Horizonte/MG:Ed. UFMG, 1997.

MORIN, Edgar. Introdução ao Pensamento Complexo. Lisboa: Instituto Piaget, 1991.

MAZZOCHI, Nílcia. Mapeando Autorias Coletivas no Acoplamento Cognição-Internet. Porto Alegre: UFRGS, 2001. Dissertação de Mestrado, Instituto de Psicologia, Universidade Federal do Rio Grande do Sul, 2001.

PIAGET, Jean. Estudos Sociológicos. Rio de Janeiro/Rj: Ed. Forenze, 1973.

RICKES, Simone. Autoria e Produção Textual. Porto Alegre: UFRGS, 1997. Dissertação de Mestrado, Faculdade de Educação, Universidade Federal do Rio Grande do Sul, 1997.

TURKLE, Sherry. Life on the Screen. Nova York:Touchstone Ed., 1997.
Referências 